\title{
TRAJETÓRIAS IDENTITÁRIAS E SENTIDOS DO TRABALHO DOCENTE PARA PROFESSORES UNIVERSITÁRIOS
}

\author{
TRAYECTORIAS DE LA IDENTIDAD Y SENTIDOS DE LA ENSEÑANZA PARA \\ PROFESORES DE LA UNIVERSIDAD \\ IDENTITARY TRAJECTORIES AND THE SIGNIFICANCE OF TEACHING FOR \\ UNIVERSITARY TEACHERS
}

Tânia Regina Raitz e Christie Dinon Lourenço da Silva Universidade do Vale do Itajai, Itajai/SC, Brasil

\begin{abstract}
RESUMO
O presente artigo é resultado de uma pesquisa que teve como objetivo compreender a trajetória identitária profissional de seis professoras universitárias e analisar os sentidos atribuídos por elas ao trabalho docente. A investigação tratou-se, metodologicamente, de uma pesquisa qualitativa. Para tanto, foram realizadas entrevistas semiestruturadas, com o uso do gravador, em que as professoras apresentaram explicações que oferecem, ao leitor, mais elementos para a compreensão de aspectos revelados sobre suas trajetórias profissionais e sobre como significam seu trabalho docente. $O$ tratamento das informações se deu por meio da análise de conteúdo. Os resultados mostram que os sentidos do trabalho, na contemporaneidade, aparecem diversificados, entrecruzados, ambivalentes e contraditórios. Essa diversidade se caracteriza pela complexidade da própria identidade, sempre em constituição, e também em razão de o mundo estar em constante mudança, especialmente o mundo do trabalho, que acaba por afetar o trabalho docente universitário, repercutindo também numa reconfiguração da identidade profissional.
\end{abstract}

Palavras-chave: trajetórias identitárias; sentidos do trabalho docente; professoras universitárias.

\section{RESUMEN}

Este artículo es el resultado de un estudio que tuvo como objetivo entender la trayectoria de identidad profesional de seis profesoras universitarias y analizar los significados que atribuyen a la enseñanza. Metodológicamente se trató de investigación cualitativa. Con este fin, fueron realizadas entrevistas semi-estructuradas, utilizando la grabadora, en la que las profesoras presentaron explicaciones que ofrecen, al lector, más elementos para la comprensión de los aspectos revelados sobre sus carreras y cómo es significada su enseñanza. El procesamiento de la información se produjo a través del análisis de contenido. Los resultados muestran que los significados del trabajo, en la contemporaneidad, aparecen diversos, entretejidos, ambivalentes y contradictorios. Esta diversidad se caracteriza por la complejidad de su propia identidad, siempre en constitución, y también debido a que el mundo está cambiando constantemente, especialmente el mundo del trabajo, que en última instancia afecta al trabajo de profesor universitario, lo que implicará también en una reconfiguración de la identidad profesional.

Palabras clave: trayectorias de identidad; método de enseñanza; profesores universitarios.

\begin{abstract}
This article is the result of a survey that aimed to understand professional identity trajectory six university professors and analyze the meanings they attribute to teaching. The investigation was treated methodologically qualitative research. To this end, semi-structured interviews, using the recorder, in which the teachers had to offer explanations, the reader, more elements for understanding aspects revealed about their career paths and how mean their teaching were performed. Processing of information occurred through content analysis. The results show that the meanings of work in contemporary appear diverse, interwoven, ambivalent and contradictory. This diversity is characterized by the complexity of their own identity, always in the constitution, and also because of the world is constantly changing, especially the world of work, which ultimately affect the university teaching job, also reflecting a reconfiguration of professional identity.
\end{abstract}

Keywords: identitary trajectories identity; significance of teaching; university teachers. 


\section{Introdução}

A temática deste estudo está relacionada à área de educação e trabalho, compõe eixos importantes para o entendimento do trabalho e seus desdobramentos para a vida das pessoas, na organização laboral, na trajetória profissional desencadeada pelo processo de trabalho no espaço universitário, âmbito de realização de tal investigação. O objetivo principal da presente pesquisa é compreender a trajetória identitária profissional de 6 (seis) professoras universitárias do curso de Pedagogia da Univali e analisar os sentidos atribuídos por elas ao trabalho docente, procurando desencadear um processo de reflexão colaborativa. As transformações relacionadas ao mundo do trabalho reforçam a relevância do desenvolvimento de pesquisas sobre os professores universitários neste contexto, no sentido de entender como ocorrem suas trajetórias identitárias associadas às dimensões subjetivas e objetivas do trabalho docente na contemporaneidade.

Os estudos acerca dos sentidos que os professores universitários atribuem ao trabalho e como constroem suas trajetórias identitárias nos espaços laborais têm sido escassos. Nesse panorama, compreende-se que as narrativas (vozes) pouco presentes nas investigações devem ser trazidas à tona e analisadas, uma vez que integram decisivamente a compreensão do trabalho e seus sentidos na construção de suas identidades. As transformações institucionais e organizacionais nas relações de produção/trabalho e implementação de políticas denominadas neoliberais no Brasil, considerando $\mathrm{o}$ atual contexto $\mathrm{e} \mathrm{o}$ processo de precarização do trabalho na contemporaneidade, atingem as Instituições de Ensino Superior; sobretudo, a trajetória identitária dos professores universitários, que revela como se constituem em seu trabalho.

Analisar o trabalho na contemporaneidade (século XXI) torna-se uma tarefa complexa. Existe uma variedade de situações que poderíamos apontar para se entender o trabalho como objeto de diversas ciências. Entretanto, não se conhecem as contradições, correlações e divergências a respeito de sua análise, bem como seu caráter multifacetado e heterogêneo, pressupondo as escolhas e problematizações da área específica para uma melhor compreensão, sem desconsiderar o contexto específico em que este é produzido (Coutinho \& Tolfo, 2007).

Neste sentido, convém salientar, conforme Navarro e Padilha (2007, p.14), que o "trabalho tem caráter plural e polissêmico e que exige conhecimento multidisciplinar". As transformações sociais, políticas, econômicas e culturais ocorridas nos últimos trinta anos - passagem do século XX ao século XXI - impuseram nova organização e estruturação do trabalho de professores universitários, provocando, consequentemente, alterações nas trajetórias identitárias desses sujeitos a partir de exigências fundamentadas na racionalidade técnica. Nesta perspectiva, o docente de ensino superior tem sido submetido a um processo de desvalorização, em decorrência da precarização das condições de seu trabalho. Em função da reestruturação produtiva e das políticas neoliberais, esses sujeitos têm vivido uma sobrecarga no trabalho e processos psicossociais que podem afetar sua saúde e bem-estar no exercício da profissão.

A profissão docente universitária, nos últimos tempos, se viu reduzida em suas atribuições (competências e habilidades técnicas) em virtude das intensas transformações no mundo do trabalho, principalmente nas instituições privadas, que impõem graus de excelência em sua produção, redimensionando tempo e espaço em suas trajetórias profissionais e novas dimensões dos sentidos do trabalho. O trabalho docente se caracteriza por elementos diferenciados, instrumentos e conhecimentos distintos. A concepção de mudança que configura o mundo do trabalho docente na atualidade torna-se fundamental para a reflexão crítica sobre os modelos teóricos do trabalho e como referência à análise das trajetórias profissionais.

Esta constatação aponta para a necessidade e uma atuação mais efetiva do campo de conhecimento da Educação e do Trabalho, em termos de vislumbrar pesquisas que possam fundamentar o entendimento de que o trabalho, assalariado ou não, ocupa lugar central na vida das pessoas e no funcionamento da dinâmica social. Coutinho, Krawulski e Soares (2007) nos trazem uma compreensão de que o trabalho é um elemento imprescindível para a construção da identidade do sujeito, todavia, não deixam de problematizar que os impactos das diversas mudanças no mundo produtivo na contemporaneidade exigem dos sujeitos novas identificações, como também o reconhecimento, em suas trajetórias, de uma dimensão temporal que integra passado e futuro no espaço do trabalho. Assim, as autoras mencionam as intensas modificações no desenho do trabalho na contemporaneidade com características como precariedade, vulnerabilidade e fragmentação, resultando em obstáculos nas identificações dos sujeitos com sua atividade, consequentemente, na construção das identidades profissionais. 


\section{Historicidade do trabalho e a diversidade de sentidos na contemporaneidade}

A partir da década de 70 do século XX, percebese um esgotamento do padrão de acumulação nomeado taylorista/fordista, cujas características têm sido assinaladas por diversos autores, como uma crise estrutural do capital (Antunes, 2003; Harvey, 2000; Mészáros, 1998, e outros). Tal crise, segundo esses autores, tem sua origem na tendência de diminuição da taxa de lucro, na incapacidade do capital de se reproduzir em grandes escalas em função do aumento da produtividade e taxas de lucratividade adequadas aos seus investimentos. Desta forma, a referida crise é compreendida a partir da esfera da produção em que o modelo taylorista-fordista-keynesiano entra em retração. Os fatos que contribuem para a crise do capital estão baseados nas elevações dos preços do barril do petróleo, em 1973 e em 1979. É justamente diante deste quadro de queda nas taxas de lucratividade e de crise no regime de acumulação capitalista que emerge a chamada reestruturação produtiva, especialmente a partir da década de 90 do século XX, articulada com a ascensão das políticas neoliberais e o processo de mundialização do capital. De acordo com Harvey (2000), essa ideia se apoia na flexibilidade dos processos de trabalho, do mercado de trabalho, dos produtos e padrões de consumo.

Neste contexto contemporâneo, Pais (2005) argumenta que as próprias representações sobre o trabalho estão atualmente marcadas por instabilidades naquilo que se apresenta como turbulência, flexibilidade e impermanência nas trajetórias identitárias ou dos percursos laborais. Isto não quer dizer que o trabalho não seja uma esfera importante na vida dos indivíduos, mas ganha novas dimensões. Desse modo, é visível a própria diversidade e a heterogeneidade que caracterizam o mercado de trabalho atualmente no Brasil, levando, assim, a diferentes situações vividas por trabalhadores e trabalhadoras.

A abordagem de Marx sobre o trabalho tem sua relevância comprovada e ainda exerce influência no pensamento ocidental. É considerada até os dias atuais pelos não críticos pós-modernistas, devido à sua contribuição na concepção do sujeito no trabalho; pois sujeito e trabalho são fontes de realização, de sentido de existência humana, ou melhor, sujeito e trabalho significavam a mesma coisa. $\mathrm{O}$ sujeito era concebido como o próprio trabalho; seria, então, o trabalho que tornaria o sujeito aquilo que ele se constitui.

Algumas breves reflexões podem ser elaboradas a partir do trabalho visto por Marx (1980 e 1989), e que aqui estão ancoradas em seus pressupostos na obra $O$ Capital - livro I, volumes 1 e 2 - e nos Manuscritos Econômicos Filosóficos. Dessa forma, podem-se buscar alguns elementos para pensar o trabalho como valor, perspectiva que amplia em muito a discussão acerca de identidade profissional quando pensada como investigação. A questão do "trabalho", elaborada pelo autor, perpassa grande parte de sua obra buscando compreender a força motriz do capitalismo em suas contradições. Para Marx, a base fundamental constituída em cada sociedade humana passa pelo processo de trabalho, seres humanos cooperando entre si para fazer uso das forças da natureza e, portanto, para satisfazer as necessidades, para ele, humanas. Assim, o trabalho de cada indivíduo ou grupo de indivíduos é trabalho social no sentido de que ele contribui para as necessidades da sociedade.

Nessa relação ou processo do trabalho visto como valor positivo poder-se-ia pensar e ampliar a perspectiva do desenvolvimento integral das capacidades humanas, vindo a revelar a necessidade de uma concepção de formação emancipatória. Sugere-se que as mudanças dadas na atualidade não conseguem dar conta para que isso ocorra. Conforme Marx, o trabalho no modo de produção capitalista deixa de hominizar e passa a alienar, já que o produto e o próprio processo de produção tornam-se estranhos ao trabalhador (Antunes, 2003). Neste sentido, o trabalho, que deveria ser humanizador, sob o capitalismo, inverte-se, como mercadoria, e passa a ser alienante e explorador.

Pais (2005) vem reafirmar sua tese de que, apesar de o trabalho continuar mantendo o significado de obrigação, de esforço e até de sofrimento em alguns casos (aspecto negativo), o certo é que alguns diagnósticos recentes mostram uma outra realidade em relação ao emprego e trabalho, que aparecem de forma ambivalente ou ambígua, em seus dois aspectos (negativo e positivo). O trabalho também continua sendo um componente central na vida dos indivíduos, porém, passa pelo desejo de um trabalho que esteja mais carregado de elementos de liberdade e autonomia (aspecto positivo); ou o papel do trabalho como uma categoria fundante do ser humano e de suas formas de sociabilidade, não sendo possível removê-lo da sociedade, uma vez que sua importância é central para a análise dos processos sociais, mesmo com os quadros de reestruturação produtiva e suas implicações, bem como as mutabilidades que vem sofrendo (Antunes, 2003).

Contudo, não podemos negar que "as mudanças nas formas de trabalho e emprego na atualidade trazem implicações objetivas e subjetivas ... envolve tanto as condições socioeconômicas nas quais essa 
atividade humana desenvolve-se, como o significado, o sentido e o valor socioculturais dessa experiência" (Blanch, 2003, citado por Coutinho, 2009, p. 192). Segundo Coutinho (2009), isto representa que as condições de trabalho são associadas às circunstâncias nas quais ele ocorre. Já os significados levam aos diferentes valores e concepções sobre trabalho. Tolfo e Piccinini $(2007$, p. 39) enfatizam que a "temática dos significados e sentidos do trabalho é pesquisada por diferentes autores com base em diversas vertentes epistemológicas". Não vamos, neste artigo, entrar nas várias discussões existentes sobre a temática, porém reconhecemos a sua existência.

No momento, é importante registrar que serão usados sentidos, como ressaltam Tolfo e Piccinini (2007, p. 44), como "uma produção pessoal decorrente da apreensão individual dos significados coletivos, nas experiências cotidianas". Portanto, consideram que essas "transformações que os sentidos e significados sofrem, são construídos por meio de uma relação dialética com a realidade". No próximo item, apresentar-se-ão as articulações possíveis entre trabalho docente e trajetórias profissionais.

No debate sobre as trajetórias identitárias na contemporaneidade, Melucci (2004), ao abordar a questão da identidade, se refere sempre a um processo relacional e social, que é mantido dialeticamente em suas dimensões biológicas e culturais, dando ao indivíduo uma capacidade plástica, ao longo de sua maturação, em modelar-se diante de novas circunstâncias e no desenvolvimento de novas funções. Maheirie (2002, pp. 39-40), na perspectiva da Psicologia Social, contribui de maneira significativa quando descreve o processo de constituição de sujeito, subjetividade e identidade numa visão ontológica. A autora menciona que, neste processo, "sujeito ou identidade" se constroem por "oposições, conflitos e negociações", sendo a identidade "constantemente inventada pelos sujeitos, em um processo aberto, nunca acabado". A subjetividade se constitui numa dimensão deste sujeito, bem como a objetividade materializada pelas relações sociais (afetivas e reflexivas), que produz significados singulares e coletivos. Desse modo, o conceito de identidade ganha um sentido dialético, pois é contraditório, múltiplo e mutável. Ela resgata alguns autores que tratam do tema para definila como um conceito polissêmico que se traduz numa síntese de identificações em curso. Portanto, para Maheirie (2002, p. 41), a constituição da identidade traz a "marca da ambiguidade, da síntese inacabada de contrários, daquilo que é individual e coletivo, daquilo que é próprio e alheio, do que é igual e diferente". Assim, ora aponta para um polo, ora para outro.
Muitas das ideias de Melucci (2004) relativas à "ação individual” são, como em Maheirie (2002), propostas para tratar da ação coletiva. Em sua abordagem orientada para os movimentos sociais, tem como objetivo investigar como os atores constroem suas ações. Na atualidade, a perplexidade se expressa mais exatamente pela perda de sentido e desvalorização do trabalho, causando decepção nos sujeitos da sociedade contemporânea, pois o trabalho já não atende aos anseios dos sujeitos, que dele esperam muito mais do aquilo que tem significado atualmente. Isso em função do modo como foi institucionalizado através do emprego, e também pelas indagações que emergiram dessa situação sobre os significados dos termos ser, sujeito e identidade (Bendassolli, 2007).

No entanto, por mais que se anuncie a morte do trabalho, ele existirá sempre, mesmo que proposto por alternativas diversificadas ou líquidas, e mostrado nas diversas identidades profissionais. Por ter se tornado um bem raro, o emprego condiciona a construção das identidades sociais e profissionais; por passar por mudanças impressionantes, o trabalho obriga transformações identitárias delicadas e, por acompanhar cada vez mais todas as modificações do trabalho e do emprego, a formação intervém nas dinâmicas identitárias muito além do período escolar (Dubar, 2005), como poderemos observar mais adiante na análise das entrevistas com as professoras universitárias.

Talvez isso se deva ao vínculo profundo, pontuado por Dubar (2005), entre emprego e formação na construção da identidade profissional, por se caracterizar, segundo o autor, numa das mais importantes dimensões identitárias na vida dos atores sociais na atualidade. Ele defende a tese da centralidade do trabalho na vida pessoal e do lugar eminente das identificações profissionais na vida social, porque apesar de todo o contexto econômico e social de "crise", não é suficientemente embasado por todos os tipos de pesquisa para defender tal posição. A privação de trabalho é um sofrimento íntimo, um golpe na autoestima, tanto quanto uma perda de relação com os outros: uma ferida identitária geradora de desorganização social, de acordo com Dubar (2005). Para o autor, todas as formas identitárias, especialmente a profissional - neste caso específico no processo de socialização das professoras universitárias -, sempre se realizam a partir das relações sociais estabelecidas com os atores, através de suas trajetórias subjetivas.

Nesta perspectiva, Mancebo (2007, pp. 76-77) diz que quando a capacidade de inventar se converte em valor principal na concorrência capitalista, as instituições de ensino - neste caso, de ensino superior 
- são atravessadas por novos elementos, resultando numa produção científica transformada em força produtiva. Portanto, esta determinação do trabalho muda para aqueles que o produzem, "fazendo com que as instituições de ensino superior sejam convidadas não só a se adaptar às novas composições trabalhistas, como também ajustar seu produto às exigências mais recentes do capital". A autora, dando sequência ao seu pensamento, expõe que a "precarização do trabalho docente, quase uma regra no setor privado de educação superior, faz-se nítida até mesmo nas grandes universidades públicas, onde proliferam as (sub) contratações temporárias de professores que são pagos por hora aula ministrada em turmas de graduação".

Dubar (2005) aborda as formas identitárias que se processam nos campos do trabalho, do emprego e da formação. Dessa maneira, o mencionado autor apresenta um panorama bastante completo que define o campo da identidade profissional, que objetiva mudanças de atitudes comportamentais no trabalho, ampliação de competências para novas exigências e inserção em novos postos de serviços, empregos em outras empresas. Neste cenário de mudanças, há uma reconfiguração das formas identitárias que,

Desta forma, levando em consideração o contex to atual da globalização das trocas econômicas, a flexibilização dos mercados de emprego e a reticularização das formas de organização provocaram uma reconfiguração das formas identitárias no campo profissional: as identidades "de rede" são potencialmente as mais valorizadas. Supõem mobilidades voluntárias "externas" e formas de acumulação de competências "distintivas" que desenham percursos profissionais de um novo tipo. (Demazière \& Dubar, 2006, p. 186, citado por Coutinho, 2009, p. 194)

Todavia, para que os sujeitos possam construir suas identidades profissionais e sociais, necessitam, ainda, ter experiências nas relações e atividades de trabalho, realizar intervenções nas representações coletivas (Dubar, 2005). Assim, o espaço do trabalho, caracterizado por divergentes experiências, passa a ser considerado um lugar privilegiado para a realização de seus anseios de reconhecimento profissional. Nesse sentido, o resultado de confronto-enfrentamento a que Dubar se refere resulta num engajamento, ou não, da identidade do sujeito no trabalho.

Os professores universitários da instituição analisada têm vivido processo semelhante aos outros trabalhadores, inúmeras mudanças têm ocorrido ou estão em processo, justificando uma reflexão que busque compreender as trajetórias identitárias e os sentidos atribuídos ao trabalho por tais sujeitos. No contexto apresentado até aqui, tudo indica que o trabalho do docente universitário vem sendo afetado tanto pelas transformações em curso quanto pela reorganização da esfera pública, de acordo com os interesses do capital, isto é, pela implementação das denominadas políticas neoliberais.

\section{Caminho metodológico trilhado: instrumentos de coleta, sujeitos e tratamento dos dados}

O presente estudo refere-se a uma pesquisa de abordagem qualitativa, realizada por meio de um roteiro de entrevistas (semiestruturadas) gravadas em áudio, com 6 (seis) professoras universitárias do curso de Pedagogia da Univali. As professoras participantes são formadas em Pedagogia e possuem Mestrado e Doutorado na área da Educação. Além do curso de Pedagogia, também atuam no Programa de Pós-Graduação em Educação da mesma instituição e todas têm mais de 15 anos de profissão. $\mathrm{O}$ roteiro das entrevistas procurou traçar um panorama que também contemplasse a percepção de como as professoras construíram suas trajetórias identitárias profissionais, a partir de suas próprias vozes. Os dados coletados foram interpretados mediante análise de conteúdo e resultaram nos seguintes eixos: (a) identificação das professoras, (b) sentidos do trabalho docente e lugar do trabalho, e (c) construção da trajetória identitária das professoras universitárias.

Rauen (2006) também é uma referência importante, pois destaca que as entrevistas se definem como uma listagem de indagações escritas e se caracterizam pela sistematização das questões que se ordenam conforme critérios estabelecidos no estudo de caso. $O$ universo desta pesquisa compreende o espaço de trabalho dos professores universitários, as universidades privadas, especificamente, a Universidade do Vale do Itajaí, localizada em Itajaí, no Estado de Santa Catarina. Trata-se de um estudo de caso, que usa como técnica de definição de amostragem; a intencional. Como se trata de uma pesquisa qualitativa, este estudo integra entrevistas com 6 (seis) professoras da instituição analisada.

Com as transformações no mundo do trabalho e como organização social, a Univali-Itajaí também carrega uma crise alicerçada nas transformações econômicas, sociais, políticas e culturais na contemporaneidade. Apesar de a Universidade ser uma organização interdependente, escolheuse, como população do estudo, os professores universitários pertencentes ao curso de Pedagogia. A unidade de análise proposta para a pesquisa corresponde ao indivíduo e ao grupo, em relação ao nível de análise organizacional. Um dos principais 
critérios adotados foi o tempo de trabalho (10 anos no mínimo) na Instituição.

A discussão engendrada sobre trabalho e qualidade de vida, de forma eminentemente qualitativa, aparece "como se fosse uma medida que juntasse, ao mesmo tempo, o sentimento e o bem-estar, a visão da finitude dos meios para alcançá-lo e a disposição para solidariamente, ampliar as possibilidades presentes e futuras" (Minayo, 2002, p. 174). Desse modo, foi importante a recordação de episódios vividos pelas professoras, a sua interpretação e a articulação temporal do passado, presente e futuro. Portanto, conforme Demaziére e Dubar (1999), os sujeitos se inserem numa história com um sentido, quando se leva em consideração as trajetórias profissionais e formas identitárias por meio do trabalho. Para o desenvolvimento desta pesquisa, foi considerada a identidade profissional como um processo permanente e relacional, contínuo, subjetivo, que vislumbra as trajetórias individuais e sociais, a partir das quais se atribui sentido ao trabalho.

Os procedimentos éticos foram contemplados na execução compartilhada, sob a forma do Termo de Consentimento para uso de voz das 6 (seis) professoras universitárias selecionadas que aceitaram participar desta pesquisa, submetida e aprovada pelo Comitê de Ética da Instituição.

O tratamento dos dados da pesquisa (informações advindas das entrevistas individuais com as professoras) foi realizado com base nos procedimentos da análise de conteúdo. Assim, conforme Franco (2005), as repetições, frequências das falas, significados e sentidos foram analisados a partir de contribuições importantes de autores que proporcionaram arranjos, pontes, caminhos, novas questões, enfim, ajudaram nas conexões e interlocuções na análise de conteúdo.

\section{Sentidos do trabalho e trajetórias identitárias dos professores universitários}

As entrevistas foram importantes para registrar as marcas narrativas das professoras universitárias. Quando questionadas sobre o lugar que o trabalho ocupa em suas vidas, as respostas foram muito interessantes, pois revelam o trabalho como construção identitária. Isto não significa dizer que o trabalho é o único universo de inclusão para as professoras universitárias, a construção identitária ocorre também por meio de outros espaços. Entretanto, o trabalho incorpora dimensões como socialibidade, neste caso, formas solidárias de viver e interagir com o outro. $\mathrm{O}$ trabalho também adquire uma dimensão humana, visto que é por meio dele que resgatamos vários sentimentos em nossas experiências profissionais. Conforme depoimentos de algumas das professoras, é possível perceber a centralidade do trabalho em suas vidas:

"O homem se realiza na vida pelo trabalho. Principalmente o nosso trabalho que é com seres humanos, não é um trabalho burocrático, preso, mas se trabalha com sujeitos. O trabalho edifica” (Sujeito 2).

"Trabalho é tudo, acho que completa a gente. Tu tem que fazer uma coisa que tu goste, que se sinta estimulado” (Sujeito 3).

"É muito importante, eu gosto muito do que faço. Numa escala de 0 a 100, ele é quase 80. Eu sei que isso é um problema, um defeito, mas é isso mesmo, 80" (Sujeito 4).

A base da vida é o trabalho. Na verdade, eu aprendi isso em casa; desde pequenininha eu já tinha minhas funções e desde lá só trabalho. Então, assim, o trabalho é central na minha vida. Se ele deve ser central ou não, é outra discussão, mas do jeito que eu fui crescendo e as condições que eu tive pra estudar e tudo, sempre foi o trabalho. (Sujeito 5)

Mas se eu pesar o meu tempo, em termos de importância e o que ele me toma, de 24 horas, 18 horas, portanto, entende-se que a importância dele é suprema, é suprema. Ele é ditador, ele chega a ser ditador no meu caso. (Sujeito 6)

Ao mesmo tempo em que comentaram sobre a importância do trabalho, as entrevistadas também trouxeram informações essenciais a respeito da sobrecarga de trabalho, em razão do desempenho de funções que vão além de suas competências e responsabilidades. A ampliação da rotina de trabalho em casa, e nos finais de semana, demonstra o grau de satisfação ou insatisfação com a racionalidade técnica instituída na organização de que fazem parte. Este fator acaba por pressionar e contribui para o excesso de trabalho. A algumas falas, transcritas a seguir, expressam essa problemática:

Às vezes nós temos essa sensação, mas não tem como dizer "isso não faz parte do meu trabalho", porque nós vivemos com seres humanos, numa instituição extremamente complexa, que é a instituição educacional, seja educação básica ou ensino superior. Quem se assume, hoje, como professor tem que ter clareza que tem que lidar com toda essa diversidade e complexidade que é o ambiente educacional. Sempre tem trabalho pra fazer em casa. (Sujeito 1)

Eu não sei se é especificidade dessa instituição ou se é geral, mas muitas vezes, pra fazer aquilo que tu queres, não tens como dizer que só vai fazer isso 
porque é a minha função. Então, tem situações que para o teu trabalho ficar bem, tens que dar uma volta e fazer acontecer em torno. Eu tenho sempre o dobro pra fazer em casa e nas férias inclusive... Bastante, sábado nem sempre, mas tem vezes que é sábado e domingo, mas o domingo é inevitável. A leitura do que meus alunos produzem é praticamente feita só em casa, porque aqui a gente não tem condição de ler ou de escrever, que incluem as demandas pra publicar, projetos pra escrever, tudo isso em casa, correção, publicação de notas, atendimento ao aluno de mestrado. (Sujeito 4)

Sim, constantemente. Eu tenho que fazer tudo, não tem ninguém pra ajudar em nada, absolutamente nada, eu não tenho nenhuma retaguarda. Quando eu digo somos nós professores, não tenho nenhum apoio, você faz sozinho tudo. Nos fins de semana, só se eu decido não trabalhar, mas eu necessito pra dar conta da minha carga ou então eu tenho que trabalhar todas as noites até de madrugada. Isso é uma realidade, pra liberar o final de semana. Eu sempre tenho trabalho em casa, sempre, sempre, sempre. Isso é uma constância, e até onde eu sei, os professores não têm hora-atividade, nós não temos. (Sujeito 5)

Os referidos depoimentos evidenciam que o sujeito, na sociedade atual, se vê diante de vários dilemas no trabalho. Suas insatisfações ou não, no contexto das sociedades complexas em permanente movimento de transformação, se apresentam na perspectiva de um sujeito com características cambiantes, que se encontra num campo de ação social e de relações, contrapondo-se a ideias deterministas, de uma identidade homogênea que não dá mais conta da heterogeneidade, complexidade e pluralidade do social. É assim que essas professoras vivenciam suas experiências e trajetórias de trabalho.

Algumas professoras descrevem situações que as incomodam no seu trabalho, os momentos em que mais se sentem estressadas e se têm disposição para o lazer ou finais de semana. As respostas revelam várias situações vivenciadas por estas profissionais do ensino superior, como se pode verificar por meio de seus depoimentos:

"Depender dos outros é uma situação que me deixa estressada, depender dos outros, porque nem sempre conseguem corresponder, enfim. Depender da tecnologia, porque às vezes a gente fica com esses problemas. Falta de tempo, só isso" (Sujeito 1)

Me sinto bastante estressada, ainda mais final de semestre. A vida da gente é bem corrida. Quando eu tenho que faltar o trabalho por um motivo necessário, isso me deixa muito mal. ... quando em sala de aula, eu preparo uma aula e tem-se toda uma expectativa e ela é frustrante ... quando eu não dou conta de fazer as correções e devoluções para os alunos, isso é o que me mata mesmo, o que me deixa mais arrasada é quando eu tenho que atrasar a correção dos meus alunos. (Sujeito 4)

Eu já cheguei a faltar por não estar bem, toda a carga, gerar assim, digamos um estresse de ficar com pressão alta, de ter sinais de saúde, físico, de eu ter que ficar em casa ou de sair daqui e ir pra casa, já tiveram sim ... me sinto estressada, sinto muito estressada, muito cansada, exaurida, vontade de me jogar num canto e não fazer nada. Incomodam-me bastante algumas lógicas da instituição, algumas burocracias, atitudes ... Outro aspecto que me incomoda é o excesso de tarefas que a gente tem sem ter apoio ... Eu acho que o sistema, as condições de trabalho que a gente tem hoje-é uma coisa que incomoda muito. (Sujeito 5)

Nóvoa (1995) expõe a complexidade desta profissão nas atuais sociedades, que exige por parte dos professores uma gama de preparação profissional e uma maior autonomia no rumo de suas atividades profissionais. Portanto, os depoimentos revelam o quanto o trabalho tornou-se uma atividade racional e incessante na era moderna, quando analisamos a trajetória profissional destas professoras, o tempo livre inexiste ou é escasso. Este passou, segundo Araújo e Sachuk (2007, p.64), "a ser, por outros meios, um mero prolongamento do trabalho ... o trabalho apoderou-se de todas as esferas da vida e da existência humana". Nesta perspectiva, na contemporaneidade, de acordo com as autoras, o trabalhador "é solicitado a participar, a envolver-se e a comprometer-se com seu trabalho e carreira". Ainda, ponderam que, não levando em consideração o caráter explorador em tal contexto, esta nova situação poderá vir a possibilitar âmbitos de realização e prazer "se for capaz de apresentar significados além daqueles meramente econômicos e cuja característica maior seja a de permitir a criação humana do trabalho no sentido da autoexpressão". Portanto, é possível observar como a construção dos sentidos do trabalho ao longo da vida produtiva passou por diversas mudanças e, pelos depoimentos das professoras, fica claro que o estresse é um aspecto psicossocial que veio junto com a racionalidade do trabalho na modernidade.

Não dá para negarque as identificações continuam em curso na participação em várias instâncias onde se vive parte do que se é. $\mathrm{O}$ trabalho é uma delas. Mesmo nesta pesquisa, como se pode perceber, o trabalho emerge como central na vida dos sujeitos, mas os sentidos se modificam, ganhando ares de diversidade. O discurso significante das professoras em relação ao trabalho não deve ser tomado, ingenuamente, como uma fonte pura de sentidos, vestíbulo de significações 
indiscutíveis, pois eles se cruzam e se mesclam, são apanhados a partir dos pontos de vistas e dos lugares que os informantes ocupam em determinado contexto, numa rede de sentidos social e culturalmente construídos. Nesse processo de apreensão do real, de suas experiências, das trajetórias identitárias, o exercício se configurou numa tentativa de aproximar a produção de sentidos sobre o trabalho com seus projetos e sonhos:

É uma realização constante, porque por mais assim que pareça, nossa, é uma pessoa que só pensa em trabalho, não. O fato de trabalhar na educação quer dizer que estamos trabalhando com as relações humanas o tempo todo, então, ao mesmo tempo; que é trabalho, é um espaço de socialização e estabelecimento de relação com " $n$ " pessoas e de aprendizagem constante. (Sujeito 1)

"O sentido é tudo que eu busco, é um projeto de vida ser assim, de ter (...) de viajar, de ter contato com o novo, com o diferente e ter que buscar novos conhecimentos, de se atualizar" (Sujeito3).

$O$ sentido é que ele nos engrandece. ... E é uma profissão que você não consegue prever, não pode dizer que semestre que vem eu vou dar aula assim, então essa é a diferença da profissão docente. Além de ler, escrever e aprender muito, nós temos que saber fazer essa transposição, pra fazer o outro aprender e ainda sentir o termômetro em relação a este outro; por isso que ela não está nos livros, mas na vivência e essa é a razão da docência, nós aprendemos no nível da subjetividade. (Sujeito 4)

É a que te dá mais autonomia, é a que te dá possibilidade de inovar, que te dá possibilidade de ultrapassar barreiras, mesmo institucionais, desde que pra melhor, que contribua pra melhor para o aluno. Então eu acho que a docência é um espaço de plena satisfação. (Sujeito 5)

Aprofundando o que significa trabalhar, para estas professoras universitárias, descobremse diversos sentidos em seus depoimentos que ultrapassam a renda como mera sobrevivência. Em suas percepções se misturam sentidos de realização, socialização, aprendizagem constante, novos conhecimentos, atualização, informação, projeto de vida, crescimento, interação, relacionamentos, autonomia, inovação, sentidos que se misturam e se cruzam, resultando em diversidade. Conforme Pais (2005), os sentidos atribuídos ao trabalho apresentamse diversificados, são sentidos que se posicionam em ordens variadas, mas sempre em redes que se conectam numa total interdependência: observa-se que não há um único e principal significado, mesmo que alguns se posicionem na dianteira. Há, sim, vários significados que criam significações relevantes para o entendimento dos sentidos.

Tais falas sinalizam que a trajetória destas professoras se relaciona aos desejos configurados em seus projetos futuros, encadeados pelo que já produziram e produzem no presente (Dubar, 2005). A relevância do trabalho docente na vida de cada uma, ou o sentido que este assume na percepção delas, vem recheada de sentimentos. Todas, de uma forma ou de outra, têm muitas expectativas na área da educação, como sujeitos singulares, apropriamse do social, modificando sentidos, aspirações e práticas que se tornam educativas, interpretam e significam seu mundo e as relações que estabelecem. Essas aspirações, articuladas com seus percursos de formação, não deixam de ser um percurso de vida. As professoras se formam nas experiências, nas interações (Moita, 1992). Isto significa que as 6 (seis) professoras universitárias têm projetos e sonhos, como pode ser visto na sequência:

Entre os projetos da vida profissional, eu tenho poucos. Eu tenho dois anos pra terminar minha carreira e quero terminar com um trabalho cada vez mais expressivo ... Depois de aposentada ... penso em contribuir com essa formação que eu tenho, mas em ação social, educação de jovens e adultos, filantropia, nas igrejas que tem trabalho de assistência social com adolescentes. (Sujeito 2)

Olha, projetos são muitos. Primeiro, eu quero fazer o pós-doutorado, talvez no ano que vem. Quero fazer um estágio numa universidade no exterior ... tenho muitos projetos, quero ter mais livros, mais publicação. E dentro do projeto profissional, eu quero também parar, como qualquer outro profissional, a gente tem que vislumbrar o parar, não é pra sempre. (Sujeito 3)

Pós-doutorado, como nós fazemos parte do corpo docente do Mestrado, este é o projeto. Minhas perspectivas são: 2012, o Pós-doutorado e equilibrar as minhas horas do mestrado e da graduação. Como está muito desigual, isso amplia muito a carga de trabalho. (Sujeito 5)

Acho que não são diferentes do que eu já estou fazendo hoje. Dedicar-me à produção científica, à pesquisa, à formação stricto sensu, que é onde eu quero ficar meu tempo maior e publicar, ir pra congressos, fazer uma palestra aqui outra lá, fazer intercâmbio, fazer estágio de pesquisa em outras universidades fora do país. (Sujeito 6)

Para algumas, o presente se mostra como possibilidade, já para outras, só o futuro, em sua imprevisibilidade, balizará os acontecimentos. Portanto, apresenta-se, na concepção delas ao 
elaborarem, simbolicamente ou não, seus projetos profissionais, a necessidade de um tipo de trabalho que seja mais compatível com suas realizações, para que possam viver mais intensamente ou plenamente. Todas essas ponderações estão expostas num movimento constante, como um tecer e destecer ininterruptos de tais relações e ligações que, por si só, são inacabadas; movimento que as próprias professoras ajudam a formar, cruzando, entrelaçando os sentidos sobre o trabalho docente e suas trajetórias profissionais. Isso mostra que a identidade docente se constrói num processo relacional (Melucci, 2004), não no isolamento profissional.

Assim, "o indivíduo é, ao mesmo tempo, determinado e determinante de seu processo de interação", aspecto presente no mundo do trabalho e central na constituição do sujeito (Araújo \& Sachuk, 2007, p. 64). Dessa forma, o homem constrói a sociedade e se relaciona com o outro e consigo mesmo (Marx, 1980), numa relação dialética. Nas falas das professoras, podemos constatar que elas acabam tendo que "administrar sua vida profissional sujeita a alterações imprevisíveis frequentes", que as obrigam (instituição) a reorganizar permanentemente suas trajetórias identitárias permeadas por suas atitudes comportamentais, suas metas, rotinas de trabalho e redes de relacionamentos (Araújo \& Sachuk, 2007). Conforme as autoras, neste percurso, a instituição cobra eficiência e competência, que se expressam na capacidade de desenvolver diversas funções ao mesmo tempo, ocupar múltiplos postos, intensificando os interesses privados.

\section{Considerações finais}

O material de análise possibilitou observar a centralidade que o trabalho tem na vida dessas professoras universitárias. Sugere-se que este continue sendo um referencial importante e estruturante como lugar de construção positiva de suas trajetórias identitárias e profissionais. As experiências que vivenciam no trabalho docente representam um constante movimento circulante e transitório em seu cotidiano, no sentido de garantir reconhecimentos e múltiplas aprendizagens em suas trajetórias identitárias e profissionais, em que o passado, o presente e o futuro incorporam a permanência materializada dos sentidos do trabalho docente expressos em seus depoimentos.

Os sentidos do trabalho aparecem de forma ambivalente, oscilando entre várias palavras, emergindo para além do mero sustento, como de realização, socialização, aprendizagem constante, novos conhecimentos, atualização, informação, projeto de vida, crescimento, interação, relacionamentos, autonomia, inovação, e assim por diante. Estes foram evidenciados de diversas maneiras por meio de representações, como ressalta Pais (2005). Em suma, nota-se que o trabalho não deixa de ser importante e central na vida das referidas professoras; entretanto, vem marcado por sentidos diversos justamente por causa da complexidade da própria identidade sempre em constituição, bem como pela conjuntura do mundo do trabalho nas sociedades atuais. As experiências trazidas pelos professores nesta investigação demonstram que esses estão cada vez mais sujeitos às condições precárias e intensificação do trabalho docente, fatores que foram analisados a partir da realidade social que vivenciam, numa perspectiva da Psicologia Social crítica e transformadora.

É na complexidade das relações estabelecidas no trabalho docente (o lugar do trabalho em suas vidas e seus sentidos, seus projetos e sonhos) que essas professoras universitárias constroem a sua subjetividade e estabelecem redes de relações sociais significativas. É nas múltiplas formas de viver seu trabalho e prática docente que constroem suas trajetórias identitárias, as quais, por sua vez, se apresentam ressignificadas no cotidiano da profissão, num movimento que é, ao mesmo tempo, permanente e cambiante, circundante, múltiplo na modelagem do curso de suas vidas. Tais trajetórias consideradas em movimentos, cambiantes, se moldam, muitas vezes, num período curto; outras vezes, esse se alonga na condição estabelecida no universo do ensino superior, aqui chamadas de movimentos de permanência e metamorfose na construção de suas identidades.

\section{Referências}

Antunes, R. (2003). Os sentidos do trabalho: ensaio sobre a afirmação e a negação do trabalho. São Paulo: Boitempo Editorial.

Araújo, R. R. \& Sachuk, M. I. (2007, janeiro/março). Os sentidos do trabalho e suas implicações na formação dos indivíduos inseridos nas organizações contemporâneas. Revista de Gestão USP, 14(1), 53-66.

Bendassolli, P. F (2007). Trabalho e identidade em tempos sombrios: insegurança ontológica na experiência atual com o trabalho. Aparecida, SP: Idéias \& Letras.

Coutinho, M. C. (2009). Sentidos do trabalho contemporâneo: as trajetórias identitárias como estratégia de investigação. Cadernos de Psicologia Social e do Trabalho, 12(2), 189202.

Coutinho, M. C. \& Tolfo, S. R. (2007). Implicações de programas de enxugamento para ex-trabalhadores de empresas estatais. Psicologia \& Sociedade, 19(n. spe.), 57-65.

Coutinho, M. C., Krawulski, E., \& Soares, D. H. P. (2007). Identidade e trabalho na contemporaneidade: repensando articulações possíveis. Psicologia \& Sociedade, 19(n. spe.), 29-37. 
Demaziere, D. \& Dubar, D. (1999). L'entretien biographique comme outil de l'analyse sociologique. UTIVAM - Revue de Sociologie e d'Anthropologie, 1(2) 225-239.

Dubar, C. (2005). A socialização: construção das identidades sociais e profissionais. São Paulo: Martins Fontes.

Franco, M. L. P. B. (2005). Análise de conteúdo. Brasília: Liber Livro

Harvey, D. (2000). A condição pós-moderna. São Paulo: Loyola.

Mancebo, D. (2007). Trabalho docente: subjetividade, sobreimplicação e prazer. Psicologia: Reflexão e Crítica, 20(1), 74-80.

Maheirie, K. (2002). Constituição do sujeito, subjetividade e identidade. Revista Interações, 13(2), 31-44.

Marx, K. (1980). O Capital. Rio de Janeiro: Civilização Brasileira.

Marx, K. (1989). Manuscritos econômicos- filosóficos. Lisboa: Edições 70.

Melucci, A. (2004). O Jogo do Eu. A mudança de si em uma sociedade global. São Leopoldo, RS: Unisinos.

Mészáros, I. (1998). A crise atual. São Paulo: Editora Ensaio.

Minayo, M. C. S. (2002). Pesquisa social: teoria, método e criatividade. Petrópolis, RJ: Vozes.

Moita, M. C. (1992). Percursos de formação e de transformação In A. Nóvoa (Org.), Vida de professores (p. 216). Porto: Porto Editora.

Navarro, V. L. \& Padilha, V. (2007). Dilemas do trabalho no capitalismo contemporâneo. Psicologia \& Sociedade, 19(1), 57-65.

Nóvoa, A. (1995). Profissão professor. Lisboa: Porto Editora.

Pais, J. M. (2005). Ganchos, tachos e biscates: jovens, trabalho e futuro. Porto: Ambar.
Rauen, F. (2006). Roteiros de pesquisa. Rio do Sul, SC: Nova Era.

Tolfo, S. R. \& Piccinini, V. (2007). Sentidos e significados do trabalho: explorando conceitos, variáveis e estudos empíricos brasileiros. Psicologia \& Sociedade, 19(1), 38-46.

Recebido em: 22/08/2013

Revisão em: 05/02/2014

Aceite em: 07/02/2014

Tânia Regina Raitz é professora e pesquisadora no Mestrado e Doutorado em Educação da Universidade do Vale do Itajaí, coordenadora do grupo de Pesquisa Educação e Trabalho, com pós-doutorado na Universidade de Barcelona. Endereço: Rua Jornalista Manoel de Menezes, 35, apto 304, Bloco A, Itacorubi. Florianópolis/ SC, Brasil. CEP 88034-060. E-mail: floraitz@yahoo.com.br

Christie Dinon Lourenço da Silva é formanda em Psicologia, formada em Pedagogia e estagiária no Tribunal de Justiça de Santa Catarina, foi Bolsista Probic. E-mail: christielourenco@hotmail.com

\section{Como citar:}

Raitz, T. R. \& Silva, C. D. L. (2014). Trajetórias identitárias e sentidos do trabalho docente para professores universitários. Psicologia \& Sociedade, 26(1), 204-213. 